Instituto Internacional de Investigación y Desarrollo Tecnológico Educativo INDTEC, C.A.

DOI: https://doi.org/10.29394/Scientific.issn.2542-2987.2019.4.12.11.220-239

OAI-PMH: http://www.indteca.com/ojs/index.php/Revista Scientific/oai

Ensayo Original / Original Essay

\title{
Desde la Pedagogía de la Ternura: Inicio de lo Lógico-Matemático en Preescolar
}

Autora: Beatriz Cecilia Valecillos Urdaneta Universidad Pedagógica Experimental Libertador, UPEL beatrizvalecillosdoc2010@gmail.com Trujillo, Venezuela https://orcid.org/0000-0001-9122-0145

\section{Resumen}

Hablar de aspectos que surgen de la socialización sobre pedagogía de la ternura, es hacer reseña a una mejor demarcación, de lo que se concibe por ternura. Y esto, debido a la tergiversación histórica anotada en el mundo de lo que llamamos sentimiento, amistad, cariño, amor, ternura. Por esto, el presente ensayo, tiene como propósito caracterizar la Pedagogía de la Ternura por medio del uso de recursos acordes para iniciar lo lógico-matemático en el Nivel Preescolar de Educación Inicial. Se trató la temática en cuestión dirigida a sustentar el análisis de los esbozos teóricos pertenecidos con la Pedagogía de la Ternura y los Procesos Matemáticos. Como síntesis conclusiva, viene a significar un incentivo al docente del Nivel Preescolar en la Educación Inicial, porque se ofrecen diferentes recursos, donde éste se apropie de ellos y pueda incluirlos en sus planificaciones. Además, se dan aportes para Desarrollar el Pensamiento Lógico-Matemático, que le ayudan a desarrollar habilidades del pensamiento lógico como; agrupar, ordenar, contar e ir construyendo desde las nociones infra lógicas, conceptos espaciales y temporales.

Palabras clave: ciencias de la educación; ciencia; lógica matemática; educación de la primera infancia. 


\title{
From the Pedagogy of Tenderness: Start of the Logical-Mathematical in Preschool
}

\begin{abstract}
Talking about aspects that arise from the socialization on pedagogy of tenderness, is to review a better demarcation, of what is conceived by tenderness. And this, due to the historical distortion noted in the world of what we call feeling, friendship, affection, love, tenderness. Therefore, this essay aims to characterize the Pedagogy of Tenderness through the use of appropriate resources to initiate the logical-mathematical in the Preschool Level of Initial Education. The topic in question was addressed to support the analysis of theoretical sketches pertaining to Pedagogy of Tenderness and Mathematical Processes. As a concluding synthesis, it comes to mean an incentive to the teacher of the Preschool Level in Initial Education, because different resources are offered, where it takes ownership of them and can include them in their planning. In addition, contributions are given to Develop Logical-Mathematical Thought, which help you develop logical thinking skills such as; grouping, ordering, counting and building from the infra logical notions, spatial and temporal concepts.
\end{abstract}

Keywords: education sciences; science; mathematical logic; early childhood education.

Date Received: 17-08-2018

Date Acceptance: $12-11-2018$ 


\section{Planteamiento Inicial}

Las innovaciones pedagógicas, que inundan los contextos educacionales llevan consigo elementos favorecedores de la emotividad en el individuo, para lograr que la educación, sea más humana e integral. Por esto, hubo la inquietud de la ensayista en presentar una temática, acorde a lo demostrado cómo la Pedagogía de la Ternura. Además, lo relaciona con los Procesos Matemáticos en Preescolar, insertos en el fascículo de Educación Inicial del Ministerio de Educación y Deportes (2005a): del Sistema Educativo Bolivariano, donde se establece como "Enfoque Didáctico de la Matemática en la Educación Inicial" (pág. 5).

Bajo esta perspectiva, enseñar matemática en los últimos tiempos cuenta con variadas investigaciones, marcando el ejercicio de los niños y niñas, mucho antes de su ingreso a cualquier espacio educativo, cuando en su interaccionar con el ambiente, según el fascículo de Educación Inicial de Procesos Matemáticos, Ministerio de Educación y Deportes (2005b): "han construido ciertas nociones de matemática en interacción con su entorno y con adultos que la utilizan. Este conocimiento de la vida diaria es necesario incorporarlo a procesos de construcción de la matemática como objeto presente en nuestra sociedad" (pág. 5).

Es decir, el aprendizaje en niños y niñas cursantes del Nivel Preescolar, referentes a contenidos matemáticos depende en gran parte del contexto, aunado a, las circunstancias ofrecidas por el docente para que surja este tipo de Pensamiento Lógico-Matemático. Entendiendo por pensamiento, según Gallo (2012): "es la actividad y creación de la mente; es todo aquello que es traído a existencia mediante la actividad del intelecto" (pág. 27). Es decir, pensar es formarse en actitudes para confiar en sus propias habilidades, dirigidas a buscar soluciones y tener gusto por aprender.

Asimismo, un aprendizaje referente al Pensamiento Lógico-Matemático, apoyado en la Pedagogía de la Ternura, ofrece variadas formas de enseñar 
descansados en el valor ternura, pareciendo estar fuera de moda y ser algo inusual. Por esto, relacionarse con personas que demuestren ternura y en nuestro caso entre niños y niñas del Nivel Preescolar, es tarea del docente brindar afecto por igual a los dos géneros: masculino y femenino. Según Duque, Yépez, Hernando, Bedoya y William (1998), citados en Maya (2002a), la ternura:

Es un comportamiento suave, afectuoso, cariñoso de alguien que siente el compromiso de darse; es una forma de comunicación la más generosa para expresar a quien se tiene al lado, es un lazo o vínculo que en un momento dado se requiere para el crecimiento de la vida afectiva, entre los seres humanos (pág. 47).

Por esto, en mi opinión la ternura y afectividad, forma parte de la naturaleza del individuo, pues ser docente en Educación Inicial significa ser poseedor de este valor tan significativo, representando una experiencia para considerar una definición como tal. De hecho, se observa en niños y niñas los deseos de aprender, explorar, percibir y desenvolverse ante determinadas situaciones presentadas. En ocasiones, cuando el docente no demuestra afecto, el tipo de estrategia que implementa carece de emotividad e incentivo emocional, para que éstos aprendan de forma significativa a desarrollar destrezas a avanzada edad, en este caso, para el desarrollo del Pensamiento Lógico-Matemático.

En consecuencia, las posibles causas que generan estas dificultades según mi óptica, es poca la prioridad para el progreso de las habilidades del pensamiento, capaces de permitir un desarrollo de las prematemáticas en niños y niñas cursantes del Nivel Preescolar en Educación Inicial. Aunado a esto, hay carencia de recursos e instrumentos pedagógicos que ayuden a aprender sobre esta temática, trayendo como consecuencia el ingreso al preescolar, con problemas de atención, haciendo dificultosa la labor docente con grupos muy numerosos, sin desarrollar habilidades matemáticas. 
Asimismo, la Pedagogía de la Ternura, ofrece múltiples formas de enseñar, sustentados con una óptima didáctica como eje fundamental para conseguir aprendizajes significativos en niños y niñas del Nivel Preescolar. De ahí, la importancia del ensayo mostrado, porque se pretende caracterizar la Pedagogía de la Ternura por medio del uso de recursos acordes para iniciar lo lógico-matemático en el Nivel Preescolar de Educación Inicial.

Respecto a la metodología presentada, ésta se corresponde con un ensayo estructurado en: planteamiento inicial, donde se exponen las ideas centrales que argumentarán la indagación; desarrollo argumentativo: donde aparecen posturas que avalan la revisión bibliográfica y para concluir, una síntesis concluyente con lo analizado por la ensayista, del recorrido del ensayo.

\section{Desarrollo Argumentativo}

\subsection{Devenir Histórico Discursivo de la Pedagogía de la Ternura}

Desde sus orígenes, se ha preocupado por revelar inquietud ante los sujetos implicados socialmente, que expresaban y reproducían relaciones asimétricas, injustas, discriminatorias, orientadas a que pudieran encontrar un camino de exploración, encuentro con la condición humana, permitiéndoles ser parte de su entorno social y de su especie. Así, el discurso de la Pedagogía de la Ternura, tiene su nacimiento en medio de factores políticos y sociales, ocasionando una transformación del sujeto socialmente para modificar lo cultural. En palabras de Cussiánovich (2007):

La pedagogía de la ternura desde sus inicios apunta a entronizar una espiritualidad hacia la conducta pedagógica y educativa, la relación humana en el quehacer formativo de las nuevas generaciones. Quién sabe si no es precisamente esto lo que debiéramos entender por el eros pedagógico (pág. 22).

Dicho de otra manera, las primeras reflexiones acerca de la Pedagogía 
de la Ternura, pretendían intuitivamente acercarse a lo humano como una reclamación ética a la conciencia. Por esto, la analogía pedagógica basada en la ternura es necesariamente, una relación fundada en el diálogo, en la palabra, en una nueva, es decir, centralmente subyacen los iniciales discursos de la Pedagogía de la Ternura, asimismo, localizamos la necesidad del regreso a la expresión que nos hace ser, nos permite un devenir como humanos.

\subsection{Acercamiento al Concepto de Ternura}

La palabra Ternura, es común escucharla y sentirla en contextos sociales, familiar, laboral, sin embargo, hasta ahora es sentida muy poco en los espacios educativos. Al comienzo, nos damos cuenta que el valor de ternura, es semejante a la afectividad, cariño, cortesía, amor, ser delicado en el trato, es decir, está presente, existe en las personas tal como quisiéramos, pero sin lograr una definición como tal. Es algo, que antes de estar atado a las palabras, está correspondido con el sentimiento; sentirla es inevitable, es apreciable, aunque a veces quisiéramos ignorarla, o sea, en oportunidades pudiera pasar desapercibida, sin embargo, está presente a diario al interaccionar con los demás.

Con relación a, concebir la instrucción del docente es caminar hacia una praxis que busque crear cambios en niños y niñas, por lo que Gorodokin (2005), citado por Peña (2017): lo apunta como "la acción sobre el sujeto orientado a un cambio en su ser, en el saber hacer, saber obrar y saber pensar, comprendida dentro de un nivel intermedio entre educación e instrucción" (pág. 128). Así, se puede deducir cuando son percibidos los elementos que guardan relación con las matemáticas, haciendo notar cambios vistos en la transformación de los infantes que se están formando, respecto a lo afectivo, cognoscitivo y social.

En efecto, el educador es un amigo que ayuda a cada niño/niña, 
primordialmente, a los más desprovistos y necesitados, a superarse, a crecer, a ser mejores. Según Pérez (2015): la Pedagogía de la Ternura "es ese arte de educar con cariño, con sensibilidad, para alimentar la autoestima, sanar las heridas, superar complejos de inferioridad o incapacidad. Es una pedagogía que evita herir, comparar, discriminar por motivos religiosos, raciales, físicos, sociales o culturales" (pág. 3).

De esta manera, de muy poco servirá que un docente graduado con encantadoras calificaciones en las universidades más prestigiosas, si carece de afecto, ternura, amor, como principio esencial. En educación, es inadmisible ser efectivo sin ser afectivo. En otras palabras, la Pedagogía de la Ternura se opone a la violencia, tan frecuente en este momento, observarla en contextos educativos.

Aunado a esto, son significativas las Voces Medias para Enunciar la Ternura como: el tacto, las caricias y los abrazos. El fenómeno del tacto, como expresión para enunciar ternura, es primordial para el perfeccionamiento humano, porque la evidencia científica es fuerte y diciente en personas con posiciones farsantes, que ven en él una postura de prejuicio a las caricias y el tacto como sexualidad. En palabras de Van Menen (1998), citado por Maya (2002b):

El tacto consiste en una serie completa de cualidades, habilidades y competencia. Una persona que tiene tacto posee la habilidad de saber interpretar los pensamientos, sentimientos y deseos inferiores a través de claves indirectas como gestos, comportamientos, expresión y lenguaje corporal. Una persona con tacto es como si fuera capaz de leer la vida interior de otra persona (pág. 132).

Por esto, tener tacto se constituye en una herramienta pedagógica relevante y ello significa, ser capaces de saber qué hacer o qué decir, cuando los niños/niñas están delante de nosotros, o sea el tacto se reconcilia en una expresión de la ternura. Por lo tanto, esto debe ser tomado como recurso, 
procedente a ser utilizado en los preescolares con los niños/niñas.

En ese orden de ideas, las caricias en investigaciones realizadas manifiestan que el ser humano necesita de ellas, además, de sentirse querido, así como alimentarse, dormir, respirar. Es decir, para acariciar no hay edad, todos los seres humanos respondemos a ellas, sin distingo de raza, credo, religión, ideologías...

A juicio de Jongeward y James (1977), citados por Maya (2002c): "las caricias pueden ser dadas en forma de toque físico real o por medio de alguna forma simbólica de reconocimiento como una mirada, una palabra un gesto o cualquier acto que diga: sé que estás ahí" (pág. 134). Interpretando los supuestos, debe darse y recibir caricias, porque quien acaricia también espera ser acariciado, pues hay que dar para recibir.

Así, los abrazos representan otra forma para enunciar la ternura es una caricia física, una forma de palpar, donde uno es capaz de aceptarse a sí mismo a la vez, que se ve aceptado por los demás. En palabras de Keating (1986), citado por Maya (2002d): "es agradable, aumenta la soledad, aquieta los miedos, la autoestima, abre la puerta de los sentimientos, alivia las tensiones, haciéndolo una expresión terapéutica y de desarrollo personal" (pág. 137).

Cabe considerar, cuando no se han contaminado los niños (as) con prejuicios, moralismos, debemos propiciar abrazos para evitar que se adueñen de ellos conceptos maliciosos, hipocresías, otros. Concluyendo la temática abordada, cabe preguntarse, ¿Se puede aplicar en el Nivel Preescolar, una Pedagogía de la Ternura?; La respuesta es sí, aunque ésta no se rige por reglas, técnicas en oposición de otras enseñanzas. Ésta se alimenta de didáctica viva, existencial, auténtica basada en lo cotidiano, donde el docente se comporta espontáneo, mientras dirige aprendizajes a niños (as), cursantes del Nivel Preescolar en Educación Inicial.

Mi opinión, es que el pedagogo sea modelo de sensibilidad, vocación 
a su profesión, tener amor, respeto, para que éstos en un futuro sean los hombres y mujeres formados para la vida. A continuación, relacionar la Pedagogía de la Ternura con el inicio de lo Lógico-Matemático, ha sido tema de mi interés particular porque en mi desempeño con la docencia en pregrado en la Universidad Pedagógica Experimental Libertador, Extensión Académica de Valera, Estado Trujillo, Venezuela, al concederme la asignatura Desarrollo del Pensamiento Lógico-Matemático.

Observé constantemente, no incluyen estrategias acordes en las planificaciones, hay actividades carentes de afectividad, ternura, emoción y faltas de motivación, porque pienso sería más interesante aprender los procesos matemáticos, si de verdad se lleva a las aulas la Pedagogía de la Ternura. Por esto, les presento en adelante, los elementos del Pensamiento Lógico-Matemático, con material variado y útil esperando les sea de provecho.

\subsection{Inicio de lo Lógico-Matemático en el Nivel Preescolar}

Iniciar el proceso del avance del Pensamiento Lógico-Matemático, es ir construyendo las relaciones de los niños con los objetos, igualmente, la mediación que debe hacer el docente para ayudarlos a descubrir objetos con determinados atributos. A continuación, una breve síntesis de la importancia de cada tipo de conocimiento, mediante lo físico, social y Lógico-Matemático, todos jerarquizados, sin afirmar que uno es más importante que el otro, los tres son ineludibles para obtener una ordenación del mundo.

Así pues, el conocimiento físico, son las propiedades que observamos en los objetos, es decir, la realidad externa como: color, olor, peso, textura, sabor, forma, etc. Dicho de otro modo, el niño/niña puede conducirse sobre el objeto y ver su resistencia, acción ejemplo, ver los movimientos de las pelotas en cuanto, a que ruedan, rebotan.

Asimismo, el conocimiento social se adquiere mediante la adultez e implica, normativas de cada sociedad, fundadas de forma dependiente. 
Igualmente, son transmitidos normas sociales, ni arrojar dentro de las casas sobre los vidrios. De igual manera, el conocimiento Lógico-Matemático, no se enseña como tal porque el niño/niña lo va construyendo luego de relaciones que ellos mismos crean entre los objetos, una vez asimilado nunca se olvidará, por ejemplo, nunca dirá una vaca no es un animal.

Relacionar la Pedagogía de la Ternura con el inicio de lo LógicoMatemático, ha sido tema de mi interés particular porque en mi desempeño con la docencia en pregrado en la Universidad Pedagógica Experimental Libertador, Extensión Académica Valera, Estado Trujillo, Venezuela, al desempeñarme como tutora en la asignatura Desarrollo del Pensamiento Lógico-Matemático, sentí que estos procesos eran de mi interés especial para algún día escribir sobre esta temática.

Observaba constantemente, en conversatorios con participantes que se desempeñan como docentes que no ofrecen recursos acordes para la construcción del Proceso Matemático, además hay carencia de afectividad, ternura, falta de emoción y de motivación, porque pienso sería más interesante, aprender la génesis de los procesos matemáticos, si de verdad se lleva a las aulas la Pedagogía de la Ternura.

A continuación, les presento los elementos que intervienen en la construcción del Pensamiento Lógico-Matemático, aun cuando las referencias sean de no reciente data, pero en mi intención de darles a conocer sustentos teóricos que de verdad respalden y ayuden al docente en este tema, las elegí porque considero son recursos apropiados para alcanzar los objetivos y les serán de utilidad.

2.4. Elementos del Pensamiento Lógico-Matemático: Clasificación, Seriación, Número, Espacio y Tiempo.

\subsubsection{La Clasificación: Similitudes y Diferencias}

La Clasificación, es el momento donde niños y niñas infantes exploran 
su mundo, van reuniendo, separando y organizando información para darle sentido a acciones y experiencia. La Clasificación según Hohmam y Weikart (1999a): "es el proceso de agrupar cosas de acuerdo con atributos y propiedades comunes, es una estrategia básica que utilizan los niños para organizar los materiales, personas, sucesos que forman parte de su juego" (pág. 561).

De esta manera, niños y niñas mediante este proceso de clasificar, construyen relaciones entre cosas similares y comienzan a comprender que se debe tratar equivalentemente, materiales y situaciones análogas. Desde luego, para que esto pueda cumplirse el docente deberá incentivar a los niños/as, para que exploren atributos ofreciéndoles herramientas con probabilidades de su interés.

Estos estímulos se pueden dar al proporcionar recursos como los citados por Hohmam y Weikart (1999b): “materiales domésticos, naturales con características atractivas (aceite para bebés, papel aluminio, papel lija, papel para envolver, crepé, piedras); materiales con partes movibles (herramientas, utensilios de cocina, instrumentos musicales, cámaras) y materiales que cambian (arcilla, plastilina, agua, arena" (pág. 563). En síntesis, la sugerencia de esta variedad de material, sirve al docente para respaldar un ambiente afectivo, propicio para aprender, ayudando a fortalecer los procesos inherentes a clasificar cosas, para poder reconocer similitudes y diferencias.

\subsubsection{La Seriación}

La Seriación consiste en ordenar, es decir crear series y patrones. En el Nivel Preescolar el niño/a, apenas comienza a entender cómo se va estructurando el proceso de la Seriación, o sea, ordenar objetos de acuerdo con diferencias y variaciones graduales en sus cualidades. Dando continuidad con la temática, en la seriación, Hohmam y Weikart (1999c), establecen:

Los niños asignan un orden lógico a una serie de objetos 
basados en variaciones graduales de un solo atributo (los carros de bombero de juguete acomodados desde el más grande al más pequeño) o en una secuencia de atributos que se repite (lentejuela roja, lentejuela azul, lentejuela roja, lentejuela azul). Algunas veces, los niños ya mayores en el preescolar pueden igualar una serie ordenada con otra (colocar tazas pequeñas, medianas y grandes, en platos pequeños, medianos y grandes) es una forma de seriación más avanzada (pág. 581).

Con esto se quiere demostrar que, cuando se realizan seriaciones, es ordenar conjuntos de elementos, que asiduamente, mantienen un orden entre los objetos incluidos. Asimismo, se puede percibir la reversibilidad del pensamiento cuando son invertidas las relaciones desarrolladas en actividades que implican dicho proceso. Al mismo tiempo, como sugerencia para el docente según Hohmam y Weikart (1999d):

Debe ofrecer a niños conjuntos de materiales en dos tamaños (botones, clavos, muñecas, cajas, pelotas, tambores, pinceles); materiales para que los niños puedan configurar y cambiar, ofrecer recursos para que produzcan sus propias creaciones grandes y pequeñas: materiales flexibles como: (arcilla, masa, plastilina, arena húmeda, limpiapipas, cajas, pegamento); materiales con atributos contrastantes: para ello se sugiere presentarles pares de materiales con atributos contrastantes (arena húmeda y seca; piedras ásperas y lisas; pastas para comer rizadas y planas; creyones con colores oscuros y claros). Además, presentarles diversos instrumentos musicales donde puedan tocar de forma contrastante (rápido y lento; fuerte y suave) (pág. 584).

Con esto quiero decir, referente a la diversidad de recursos que los autores sugieren, éstos sean relevantes, en la planificación del docente, su inclusión ayudará a construir debidamente, la seriación, es decir ordenar, objetos. Así, lo adquirirán niños y niñas del Nivel Preescolar en un contexto de afectividad, que será propicio, para asimilar dichos elementos, hacia una mejor repercusión y aceptación en los niños/as. 


\subsubsection{EI Número}

El concepto funcional de número, se va construyendo cuando surgen interacciones con materiales y personas. A continuación, se mencionan algunos recursos que puedan usar para realizar comparaciones referentes al número de objetos:

- Materiales Discretos: Colecciones de cuentas, bloques, carros, muñecas, botones y latas. Conviene subrayar, deben aprender a contar con la libertad de colocarlos en fila y detallar. Además, rocas, hojas, tarjetas, tapas de botellas.

- Materiales de Arte: esta área se debe equipar asiduamente, como manera de apoyarlos para contrastar el número de objetos, contenidos en sus obras de arte.

Siguiendo la idea, debe haber atención cuando los infantes observan y preguntan, el docente debe recordar que sus interrogantes deben tener un nivel mínimo. En palabras de Hohmam y Weikart (1999e): "Ios niños tienen más probabilidades de aprender de las preguntas que ellos formulan que de las que plantean los adultos" (pág. 597).

Es decir, hay que atender a sus comparaciones espontáneas, por ejemplo, al comparar número de materiales, número de cosas en representaciones (propios retratos, dibujos, revistas) y darle importancia cuando compara sus edades con las de otros niños. Así, con frecuencia cuentan haciendo corresponder uno a uno "una taza para cada plato"; "un oso para cada silla"; "un anillo para cada dedo"; esto los lleva a pensar como experiencia física con las equivalencias.

\subsubsection{El Espacio}

Espacio y Tiempo, son las llamadas Nociones Infra Lógicas, al respecto 
Piaget (1956), establece: "las nociones infra lógicas como un conjunto de estructuras exactamente isomórficas a las precedentes, salvo que se infieren a objetos continuos, se fundan en aproximaciones y separaciones... refieren a las operaciones espaciales, temporales y cinemáticas" (pág. xiii).

En otras palabras, el conocimiento infra lógico, se da con anterioridad al lógico, mediante reflexiones meditadas, que admiten dar profundidad a procesos que luego, se incorporarán al sistema de cognición de estas relaciones infra lógicas de los objetos, dando paso al conocimiento del tiempo, posibilitando lecturas de pertenencias esenciales a las cosas. Es decir, constituyen como tal a los objetos para luego ser agrupados, ordenados, comparados gracias a las estructuras lógicas.

Para ir construyendo el entendimiento básico del espacio, se observa que comienza en la primera infancia, donde siguen de forma visual el trayecto de personas y objetos, lo que los lleva a saber trasladarse por el espacio, bien sea caminando, gateando, arrastrándose a tropezones hasta alcanzar a los adultos u objetos que son de su interés.

De hecho, las relaciones espaciales la primera clasificación acerca de este conocimiento surgen de acuerdo con lo expuesto por Piaget (1948), citado por Adrada (2004a): "el cual establece y presenta que para adquirir la noción de espacio éste se construye gradualmente siguiendo un orden que se da en tres (3) etapas: Topológico, Proyectivo y Euclidiano" (pág. 5). En adelante, daré una explicación detallada de cada una de ellas, relacionadas al espacio del niño/a en edad infantil.

\subsubsection{Espacio Topológico}

Este espacio, está suscrito al cuerpo, debido a que la experiencia vivida lo perciben desde su propio cuerpo y no lo ven en un espacio adireccional. Según Adrada (2004b): "en topología está permitido doblar, estirar, encoger, retorcer, etc., los objetos, pero siempre que se hagan sin romper ni separar lo 
que está unido, ni pegar lo que estaba separado" (pág. 6).

Esto relacionado a la temática nuestra, ocurre desde que los niños/as nacen hasta los 2-3 años y lleva por nombre "inteligencia sensorio motriz". Ahora bien, las relaciones topológicas se expresan por medio de señales como: encima-debajo; más-arriba; más-abajo; delante-detrás; arriba-abajo; mediante expresiones como: doblar, estirar, pegar, amontonar, ordenar, agrupar, recortar y para formar posiciones que significa, como el último eslabón, para contribuir a alcanzar nociones espaciales e imágenes mentales, que posee el objeto respecto a nosotros.

\subsubsection{Espacio Proyectivo}

Sucede, cuando lo representado, o sea el objeto, no es visto como aislado sino en inter-coordinación con cosas. Por esto, este espacio depende de varios factores como: la distancia de lo observado y del ángulo visual de estos. Es decir, aquí se busca tener características estructurales no copia, para así encontrar diferentes representaciones/interpretaciones y no duplicar idénticamente, para generar imágenes mentales de esas representaciones.

Para comprender bien estas representaciones, primero se debe pasar por una actividad cognitiva de experiencia vivida, además de analizar el objeto representado, inmerso en un medio natural real y uno cultural específico. En palabras de Adrada (2004c): "para extraer las características estructurales más relevantes de este espacio o propósito y crearse una imagen mental de ello, que le permita su representación en otro soporte o en ausencia del objeto o situación o definidos en el tiempo" (pág. 6). Interpretando los supuestos es de inferir, sin imagen mental de algo, se hace imposible su representación, porque bien es sabido que la mano obedece a la mente para luego seguir las direcciones y relacionarse con lo poseído en la mente sin ellas, se hace totalmente imposible representarlas. 


\subsubsection{Espacio Euclidiano}

Es definido, por ejes perpendiculares entre sí. Por esto, Castro (2004): define el espacio euclidiano, como aquel donde se dan estilos relativos "al mundo de las medidas, las distancias, los ángulos subsumiéndose allí los aspectos proyectivos y topológicos que configuran, en unión con lo euclidiano, el espacio total sobre el cual se debe desarrollar nuestra capacidad de ubicación en el espacio" (pág. 163).

Dicho de otra manera, del espacio euclidiano se discurren tres dimensiones: longitud, superficie y volumen. Así, con estas tres extensiones se analiza la forma euclidiana del espacio. Sintetizando, el espacio como elemento del Pensamiento Lógico-Matemático brinda demasiado placer a niños y niñas, el simple hecho de llenar y vaciar les da satisfacción, porque ganan experiencias, cuando unen objetos (llenar), separarlos (vaciar) accionar que al transcurrir el tiempo aprenden a observar objetos juntos o separados en el espacio.

\subsubsection{El Tiempo}

Este elemento como ya se mencionó anteriormente, también corresponde a las Nociones Infra lógicas. Como concepto, el tiempo es abstracto, no lo podemos percibir con ninguno de nuestros sentidos, está basado en experiencias sensoriales y activas. Resulta claro, que los pequeños en edad preescolar, retienen imágenes mentales que les sirven para hablar y recordar acerca de cosas que le sucedieron en el pasado y anticipar actividades que quisieran realizar a futuro. Igualmente, ellos se enfocan en el presente, pueden recordar el pasado y anticipar el futuro.

En este sentido, es pertinente resaltar el postulado de la educadora Harner (1981): cuando encontró que los preescolares, "han dominado algunas de las primeras nociones, del sistema ordenado de relaciones pasadas, presentes y futuras. Cuentan con un entendimiento básico de acontecimientos 
que preceden o son posteriores al momento presente en el cual están hablando" (pág. 503).

Más aún, cuando participan en cumpleaños, días festivos, paseos, fines de semana, van generando la intuición que poseen respecto a secuencias del tiempo. Asimismo, van formando sus propios conceptos del tiempo, por ejemplo, tiempos largos y tiempos cortos, basados en experiencias de espera y apremio.

En cuanto, a segundos, minutos y horas le asignan muy poco significado los preescolares. No obstante, la socialización en que viven los adultos respecto, a la forma que se refieren a esto, a los niños y niñas le es fácil interpretarlo siguiendo sus propias experiencias, por ejemplo, la hora de acostarse, de la limpieza, de fiesta, etc.

Luego, de lo expuesto, respecto a los elementos del Pensamiento Lógico-Matemático es pertinente entender el desarrollo mental del niño/a, porque enseñar y aprender la matemática en el Nivel Preescolar, se requiere de un "docente afectivo", esto implica que su praxis pedagógica como actividad central, debe estar abocada a pedagogizar el valor ternura para lograr de forma armoniosa, afectiva en niños y niñas se puedan identificar, con cada uno de los elementos del Pensamiento Lógico-Matemático. Primeramente, su proceso de cognición servirá para dar dará paso al conocimiento LógicoMatemático.

\section{Síntesis Conclusiva}

En realidad, este ensayo, viene a significar un incentivo al docente del Nivel Preescolar en la Educación Inicial, aunque no ha tocado aspectos variados de cómo se puede aprovechar la Pedagogía de la Ternura, si lleva insertos diferentes recursos, donde el docente se apropie de ellos y pueda incluirlos en sus planificaciones.

El ensayo, abrió el terreno de forma conceptual, para señalar al vasto 
campo de elementos, que subyacen a un conciso bosquejo de aspectos a debatir, en este caso, por el docente del Nivel de Preescolar respecto, a los postulados teóricos, de reconocidos autores en la temática. Además, se dan aportes para Desarrollar el Pensamiento Lógico-Matemático, donde se destaca que al interactuar con objetos y contexto, le ayudan a desarrollar habilidades del pensamiento lógico como: agrupar, ordenar, contar e ir construyendo desde las nociones infra lógicas, conceptos espaciales y temporales.

Sobre la base del análisis de los resultados, se dio a conocer que el inicio del pensamiento lógico en el niño/a, se forma a partir de su interactuar con los objetos y las relaciones, que logran establecer con ello. Por esto, se recomienda al docente, identificar estas realidades para un buen desenvolvimiento en el futuro.

\section{Referencias}

Adrada, R. (2004a,b,c). Artes Plásticas y Cultura Visual en el Medio. EI Espacio y el Niño/a de Infantil. Departamento de Didáctica de la Expresión Musical Plástica y Corporal. España: LEIOA.

Castro, J. (2004). El Desarrollo de la Noción de Espacio en el Niño de Educación Inicial. Acción Pedagógica, 13(2), 162-170, ISSN-e: 1315401X. Recuperado de:

https://dialnet.unirioja.es/servlet/articulo?codigo=2970459

Cussiánovich, A. (2007). Aprender la Condición Humana: Ensayo sobre Pedagogía de la Ternura. ISBN: 978-9972-9291-5-1. Lince, Lima, Perú: Instituto de Formación de Educadores de Jóvenes, Adolescentes y Niños Trabajadores de América Latina y el Caribe - IFEJANT.

Gallo, O. (2012). Una Aventura por las Matemáticas... "Estrategias Pedagógicas Didácticas para Desarrollar el Pensamiento Lógico Matemático en los Niños de 3 - 4 Años, del Hogar Campanitas". 
Caldas, Bogotá, Colombia: Corporación Universitaria Lasallista Facultad de Ciencias Sociales y Educación.

Harner, L. (1981). Children Talk About the Time and Aspect of Actions. Child Development, 52(2), 498-506. Recuperado de:

https://doi.org/10.2307/1129167

Hohmam, M., \& Weikart, D. (1999a,b,c,d,e). La Educación de los Niños Pequeños en Acción. Manual para Los Profesionales de la Educación Infantil. ISBN:978-968-24-4607-8. México: Editorial Trillas. Maya, A. (2002a,b,c,d). Conceptos básicos para una Pedagogía de la Ternura. Arnobio Maya Betancourt. 1ra. Edición, ISBN: 9968-10-017-X. Cartago, Costa Rica: Impresora Obando, págs. 162.

Ministerio de Educación y Deportes (2005a,b). Educación Inicial. Procesos Matemáticos. Caracas, Venezuela: Editorial Noriega. Recuperado de: https://www.unicef.org/venezuela/spanish/educini6.pdf

Peña, J. (2017). Formación Permanente de los Docentes como Referente de la Calidad Educativa. Revista Scientific, 2(5), 125-139. Recuperado de: https://doi.org/10.29394/scientific.issn.2542-2987.2017.2.5.7.125$\underline{139}$

Pérez, A. (2015). Pedagogía del Amor y la Ternura. Blog de WordPress.com. [Documento en línea]. Recuperado de:

https://antonioperezesclarin.com/2015/03/09/pedagogia-del-amor-y-laternura

Piaget, J. (1956). The Child's Conception of Space. ISBN: 0-415-16889-9. London and New York: English translation first published 1956 by Routledge \& Kegan Paul Ltd., pp. 153-487. 


\section{Beatriz Cecilia Valecillos Urdaneta \\ e-mail: beatrizvalecillosdoc2010@gmail.com}

Nacida en Valera, Estado Trujillo, Venezuela. Actualmente, culminé estudios de posdoctorado en Estudios Libres, en la Universidad Fermín Toro (UFT), Cabudare, Barquisimeto, Estado Lara, Venezuela; Dra. en Ciencias de la Educación, egresada de la UFT; Especialista en Docencia para la Educación Inicial de la Universidad Valle del Momboy, Trujillo; Curso de actualización y Perfeccionamiento Profesional de Tutores de Trabajo Especial de Grado en el año 2009, en la Universidad Valle del Momboy, Valera, Estado Trujillo. En el presente, me desempeño como docente contratada de la Universidad Pedagógica Experimental Libertador (UPEL), Extensión Académica Valera, Trujillo; y Árbitro Calificado del Instituto Internacional de Investigación y Desarrollo Tecnológico Educativo INDTEC, C.A., Constancia expedida en Barinas el 03/07/2017 y Árbitro calificado en la Universidad Fermín Toro, Cabudare, Estado Lara, Venezuela.

El contenido de este manuscrito se difunde bajo una Licencia de Creative Commons ReconocimientoNoComercial-Compartirlgual 4.0 Internacional 